\title{
Desenvolvimento e produção de genótipos de couve manteiga
}

\author{
Maria do Carmo de SS Novo ${ }^{1}$; Angélica Prela-Pantano ${ }^{1}$; Paulo E Trani ${ }^{2}$; Sally F Blat ${ }^{3}$ \\ ${ }^{1}$ IAC-APTA, Centro de Ecofisiologia e Biofísica; ${ }^{2}$ IAC-APTA, Centro de Horticultura, C. Postal 28, 13012-970 Campinas-SP; ${ }^{3}$ APTA- \\ Polo Regional Centro Leste de Ribeirão Preto; jpsnovo@iac.sp.gov.br; angelica@iac.sp.gov.br; petrani@iac.sp.gov.br; sally@apta. \\ sp.gov.br
}

\section{RESUMO}

O experimento foi conduzido na casa de vegetação no Centro de Ecofisiologia e Biofísica do IAC, em Campinas-SP, de agosto a dezembro de 2008. As cultivares de couve Manteiga São José, Verde-Escura, IAC-Campinas, Orelha de Elefante e Vale das Garças foram avaliadas a cada quatorze dias até 126 dias após a instalação do experimento. As couves foram produzidas a partir de mudas. Os tratamentos foram dispostos em blocos ao acaso, com oito repetições com parcelas subdivididas para época de avaliação. Foram medidos a altura média de plantas e o diâmetro do caule e colhidas todas as folhas consideradas apropriadas para comercialização. Estas foram contadas, medidas suas áreas foliares e determinadas as suas biomassas frescas e secas. Contou-se ainda o número de brotações e o número de folhas totalmente expandidas que ainda não estavam apropriadas para colheita e determinou-se o número total de folhas. A cultivar Vale das Garças apresentou o maior desenvolvimento vegetativo em todas as variáveis analisadas. A 'Orelha de Elefante', por possuir folhas com área foliar específica maiores, teve biomassas fresca e seca totais semelhantes à da Vale das Garças embora tenha apresentado menor número de brotações, de folhas colhidas e total de folhas. Concluiu-se que essas duas cultivares constituem boas alternativas para a produção de couve.

Palavras-chave: Brassica oleracea L. var. acephala, desenvolvimento da planta, fisiologia de hortaliça.

\begin{abstract}
Development and yield of kale genotypes

The experiment was carried out in a glasshouse in the Centro de Ecofisiologia e Biofísica of the Instituto Agronômico de Campinas, São Paulo State, Brazil, between August and December 2008. The kale cultivars Manteiga São José, Verde-Escura, IAC-Campinas, Orelha de Elefante, and Vale das Garças were evaluated every 14 days until 126 days after planting. The kales were produced from plantlets. The experimental design was a randomized complete block with eight replications, in a split-plot design for time of evaluation. The plant height and stem diameter were measured and all commercial leaves were harvested and counted. Leaf areas were measured and their fresh and dry weights were determined. The sprout number and all totally expanded but not yet commercial leaves were counted and the total number of leaves was calculated. Vale das Garças was the cultivar with highest vegetative development for all variables analyzed. Although the sprout, commercial leaves and total number of leaves showed lower values in 'Orelha de Elefante', the final yield of fresh and dry leaves of this cultivar presented higher specific foliar area and its fresh and dry weight were similar to that of Vale das Garças. 'Vale das Garças' and 'Orelha de Elefante' presented themselves as a good alternative for kale production.
\end{abstract}

Keywords: Brassica oleracea L. var. acephala, plant development, vegetable physiology.

(Recebido para publicação em 24 de setembro de 2009; aceito em 25 de agosto de 2010) (Received on September 24, 2009; accepted on August 25, 2010)

\begin{abstract}
A couve manteiga (Brassica oleracea L. var. acephala) é uma hortaliça arbustiva anual ou bienal, da família Brassicaceae cujo consumo no Brasil tem gradativamente aumentado devido, provavelmente, às novas maneiras de utilização na culinária e às recentes descobertas da ciência quanto às suas propriedades nutricêuticas. De acordo com Camargo et al. (2008) e Camargo Filho \& Camargo (2009), em 2006, a área plantada de couve no estado de São Paulo era de 1200 ha, aumentando para 1424 ha em 2007, com produtividades de 26,7 e 28,8 toneladas por hectare, respectivamente. Segundo Lorenz \& Maynard (1988), comparativamente a outras hortaliças folhosas, a couve manteiga se destaca por seu maior conteúdo de proteínas, carboidratos, fibras, cálcio,
\end{abstract}

ferro, vitamina A, niacina e vitamina $C$. É ainda uma excelente fonte de carotenóides apresentando, entre as hortaliças, maiores concentrações de luteína e beta caroteno, reduzindo riscos de câncer no pulmão e de doenças oftalmológicas crônicas como cataratas (Lefsrud et al., 2007).

É uma cultura típica de outonoinverno se desenvolvendo melhor em temperaturas mais amenas $\left(16\right.$ a $\left.22^{\circ} \mathrm{C}\right)$, apresentando certa tolerância ao calor podendo, em alguns locais, ser plantada ao longo de todo ano (Filgueira, 2000). Pode permanecer produtiva por vários meses, mas é altamente exigente em água (Hussar et al., 2004). Segundo Camargo (1984), no estado de São Paulo, produções mais elevadas são obtidas de abril a novembro. Em temperaturas infe- riores a $10-5^{\circ} \mathrm{C}$, a couve tende a florescer fato que não é desejável, pois paralisa a produção de folhas comerciais.

Existem diversas cultivares da couve manteiga, sendo classificadas quanto à aparência, cor e textura das folhas. O banco de germoplasma de couve no IAC conta com 33 genótipos com grande diversidade morfológica e genética (Sawazaki et al., 1997). Para a facilidade de identificação no campo, esses materiais foram nomeados, desde a década de 40, por letras do alfabeto conforme a cronologia de sua introdução. Mais recentemente, após a listagem alfabética ter se encerrado, para a introdução de novos materias adotou-se nomenclatura baseada nos locais de origem dos mesmos. No estado de São Paulo, a cultivar do grupo denominado de 'Manteiga' 
é a de maior aceitação comercial por possuir folhas com limbo verde claro, tenras, lisas ou pouco onduladas e com pecíolos e nervuras verdes bem claras (Camargo, 1984).

As cultivares de couve manteiga apresentam diferentes padrões de altura. Segundo Nieuwhof (1969), cultivares que apresentam plantas de 40-80 cm de altura são classificadas de média a alta e aquelas com pelo menos $90 \mathrm{~cm}$, de altas. As plantas da maioria das cultivares comercializada no Brasil são de porte médio a alto. No estado de São Paulo, $90 \%$ das cultivares de couve são multiplicadas por mudas e estas têm como características plantas com porte alto. $\mathrm{Na}$ fase de colheita, quando a altura das plantas varia entre 60 e $100 \mathrm{~cm}$, muitas vezes, se faz necessário estaqueá-las. As cultivares compactas, com altura inferior a $50 \mathrm{~cm}$, híbridas, multiplicadas por sementes, são pouco cultivadas devido a características morfológicas não atrativas para o consumidor. Apresentam folhas de cor mais escura, nervuras proeminentes e de cor clara, que o consumidor associa a maior tempo de cocção. O objetivo do trabalho foi avaliar cinco genótipos de couve manteiga, com diferentes aspectos fenológicos quanto ao seu desenvolvimento com ênfase na produção de folhas.

\section{MATERIAL E MÉTODOS}

O experimento foi conduzido nas dependências do Centro Experimental, do Instituto Agronômico, Campinas-SP, de agosto a dezembro de 2008 , em casa de vegetação não climatizada $(6,60 \mathrm{~m}$ de largura x 7,70 m de comprimento x 3,00 $\mathrm{m}$ de altura), coberta com vidro transparente, com possibilidade das laterais serem abertas para facilitar a ventilação. Foram avaliadas as cultivares de couve da coleção de germoplasma do IAC descritas a seguir: Manteiga São José (N), Verde-Escura (P), IAC-Campinas (CP), Orelha de Elefante (U) e Vale das Garças (V).

As mudas foram formadas pelo sistema de estaquia verde coletando-se as brotações laterais, com três a quatro centímetros de altura e dois folíolos, no terço basal das plantas matrizes. Os vasos plásticos empregados na produção de mudas eram de cor preta, com diâmetro superior de $8 \mathrm{~cm}$ e $0,5 \mathrm{~L}$ de capacidade. As mudas das cultivares Manteiga São José (N), Verde-Escura (V), Orelha de Elefante (U) e Vale das Garças (V) foram coletadas de plantas que estavam com 110 dias de idade no campo e as de 'IAC-Campinas' (CP) com 54. Essas foram plantadas em substrato da marca comercial Plantmax HA, composto de casca de pinus carbonizada e vermiculita e, formadas em estufa com cobertura plástica de polietileno transparente, com trama de $150 \mu \mathrm{m}$, e com laterais cobertas com tela tipo sombrite de $2 \mathrm{~mm}$ de abertura, desde a superfície do solo até dois metros de altura.

A ocorrência de baixas temperaturas $\left(12-15^{\circ} \mathrm{C}\right)$ dificultou o desenvolvimento das mudas atrasando o transplantio. As mudas, com sete a oito centímetros de altura, vigorosas, bem formadas e bem enraizadas, foram transplantadas 45 dias após o inicio de sua formação, para vasos plásticos, com formato trapezoidal (diâmetro maior de 25,6 cm, diâmetro menor de $16,2 \mathrm{~cm}$ e altura de 22,5 cm). $\mathrm{O}$ vasos foram preenchidos com solo classificado como Latossolo Vermelho distrófico, peneirado (malha de $4 \mathrm{~mm}$ ) e dispostos sobre mesas de concreto com 2,50 m de comprimento e $0,85 \mathrm{~m}$ de largura, em casa de vegetação. Em cada vaso foram colocados oito litros de terra.

Os resultados da análise química e granulométrica de amostra composta coletada nos vasos do experimento foram: matéria orgânica: $21 \mathrm{~g} \mathrm{dm}^{-3} ; \mathrm{pH}$ em $\mathrm{CaCl}_{2}: 6,1$; P resina: $6 \mathrm{mmol}_{\mathrm{c}} \mathrm{dm}^{-3}$; $\mathrm{K}: 0,8 \mathrm{mmol}_{\mathrm{c}} \mathrm{dm}^{-3}$; $\mathrm{Ca}: 23 \mathrm{mmol}_{\mathrm{c}} \mathrm{dm}^{-3}$; Mg: $9 \mathrm{mmol}_{\mathrm{c}} \mathrm{dm}^{-3}$; $\mathrm{H}+\mathrm{Al}: 15 \mathrm{mmol}_{\mathrm{c}}$ $\mathrm{dm}^{-3}$; SB: $23 \mathrm{mmol}_{\mathrm{c}} \mathrm{dm}^{-3}$; CTC: 48 mmol dm${ }^{-3}$; V: 69\%; Fe: $8 \mathrm{mg} \mathrm{dm}^{-3}$; Mn:

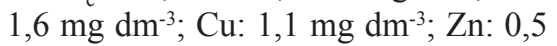
$\mathrm{mg} \mathrm{dm}{ }^{-3} \mathrm{e}$ B: $0,13 \mathrm{mg} \mathrm{dm}^{-3}$, argila: 390 $\mathrm{g} \mathrm{kg}^{-1}$, silte $80 \mathrm{~g} \mathrm{~kg}^{-1}$, areia grossa: 340 $\mathrm{g} \mathrm{kg}^{-1}$, areia fina: $190 \mathrm{~g} \mathrm{~kg}^{-1}$. O solo foi corrigido com o equivalente a $1 \mathrm{t} \mathrm{ha}^{-1} \mathrm{de}$ calcário dolomítico fino (PRNT=90\%) trinta dias antes do transplantio. Quinze dias após a aplicação do calcário foi aplicado ao solo o equivalente a $200 \mathrm{~kg}$ ha $^{-1}$ de $\mathrm{P}_{2} \mathrm{O}_{5}$ (superfosfato simples), 90 $\mathrm{kg} \mathrm{ha}^{-1}$ de $\mathrm{K}_{2} \mathrm{O}$ (sulfato de potássio) e $0,5 \mathrm{~kg} \mathrm{ha}^{-1}$ de B (bórax). As coberturas nitrogenadas iniciaram-se catorze dias após o plantio aplicando-se o equivalente a $20 \mathrm{~kg} \mathrm{ha}^{-1}$ de $\mathrm{N}$ na forma de nitrato de amônio. $\mathrm{Na}$ metade do ciclo, com o crescimento das plantas, aumentaram-se as doses para o equivalente a $30 \mathrm{~kg} \mathrm{ha}^{-1}$ de $\mathrm{N}$ empregando-se o mesmo fertilizante nitrogenado. Após o transplantio, os vasos foram irrigados até a percolação da solução do solo sendo colocada na superfície dos vasos uma camada de um centímetro de vermiculita. Durante o experimento os vasos foram irrigados sempre que necessário. Aos 79 dias após o inicio do experimento, as plantas de todas as cultivares foram tutoradas com estacas de bambu para evitar a quebra das hastes.

Os vasos foram dispostos em blocos ao acaso, com oito repetições com parcelas subdivididas para época de avaliação sendo que cada parcela era constituída por um vaso. As avaliações foram realizadas aos 14, 28, 42, 56, 70, $84,98,112$ e 126 dias após a instalação do experimento.

Em cada avaliação foram medidas, com régua, a altura de plantas (a partir do nível do solo até a extremidade das folhas mais altas) e o diâmetro do caule (medido com paquímetro na metade da altura da planta). Foram também avaliados o número de folhas apropriadas para a comercialização (número de folhas maiores que $8 \mathrm{~cm}$, partindo-se das folhas basais até a última folha com o tamanho pertinente) e o total de folhas na planta. A colheita das folhas foi realizada cortando-se o pecíolo rente ao caule. Foram medidas suas áreas foliares (em integrador de área foliar LI-COR 3100) e calculou-se a área foliar por planta e por folha (área foliar específica) e determinadas suas biomassas frescas e secas (determinada em estufa com ventilação forçada de ar a $65^{\circ} \mathrm{C}$ até atingir a massa constante). Visando ainda estimar a possibilidade de produção de mudas pelo agricultor, contou-se o número de brotações, as quais foram retiradas das plantas e descartadas após a contagem pois, segundo Tavares et al. (1998), se os brotos são deixados nas axilas das folhas há redução no desenvolvimento da planta e dificuldade no controle de pulgões, praga muito comum nesta cultura. Os pulgões, quando no início de 
sua incidência, foram controlados com deltametrina em alternância com Neem. Para prevenção de oídio foram realizadas aplicações de leite cru a 5\%.

A análise de variância dos resultados foi feita usando o software Excel, de acordo com o método para experimentos em parcelas subdivididas (Steel \& Torrei, 1980), empregando-se o teste de Duncan a 5\% de probabilidade para a comparação entre as médias das cultivares e regressão polinomial para os efeitos de épocas. Como foi observada heterogeneidade da variância, os dados de número médio de folhas colhidas e total de folhas e de brotações foram transformados em $\sqrt{x+1}$ para análise estatística, mas nas tabelas são apresentados os dados originais.

\section{RESULTADOS E DISCUSSÃO}

Em todas as épocas de avaliação, a cultivar Vale das Garças (V) apresentou plantas com maior altura média e a 'Manteiga São José' (N), a menor (Figura 1A). Nas avaliações realizadas aos 14 e aos 42 dias, as plantas da cultivar Verde-Escura (P) não diferiram em altura daquelas da 'Vale das Garças' (V). Aos 112 dias a cultivar Manteiga São José (N) apresentou plantas de porte mais baixo que a 'Verde-Escura' $(\mathrm{P})$ e 'Vale das Garças' (V), não diferindo estatisticamente das demais. Para todas as cultivares, as alturas médias das plantas de couve aumentaram linearmente em função do tempo (Figura 1A), indicando que as condições do ambiente onde as plantas se desenvolviam estavam favoráveis. Segundo Niewhof (1969), as cultivares de couve de porte médio a alto são as preferidas pelos agricultores, pois suas folhas são mais facilmente colhidas. Cabe ressaltar que, embora quinzenalmente as plantas tivessem sido adubadas, apenas a cultivar Vale das Garças (V) apresentou, no final do ciclo, plantas com altura média superior a $1,00 \mathrm{~m}$.

Em relação ao diâmetro médio do caule das plantas, a partir dos 42 dias após o início do experimento, as cultivares Verde-Escura (P), Orelha de Elefante (U) e Vale das Garças (V) não diferiram entre si (Figura 1B). A cultivar IACCampinas (CP) foi a que apresentou

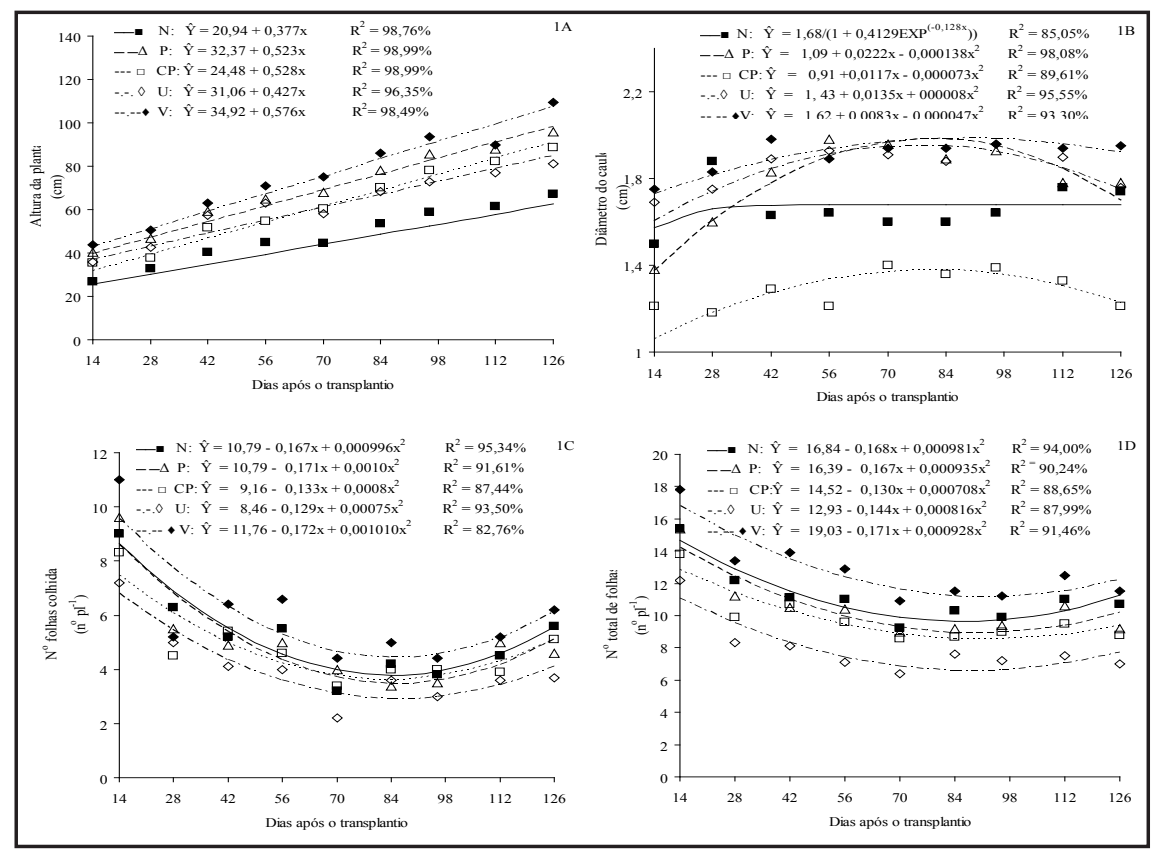

Figura 1. Diferenças entre as cultivares de couve Manteiga São José (N), Verde-Escura (P), IAC-Campinas (CP), Orelha de Elefante (U) e Vale das Garças (V) quanto à altura média de plantas, diâmetro médio do caule e número de folhas colhidas e total de folhas, por planta, dos 14 aos 126 dias após a instalação do experimento [differences in plant height, stem diameter, and number of leaves and total number of leaves in a plant from 14 to 126 days after the beginning of the assay among kale cultivars Manteiga São José (N), Verde-Escura (P), IACCampinas (CP), Orelha de Elefante (U) and Vale das Garças (V)]. Campinas, IAC, 2008.

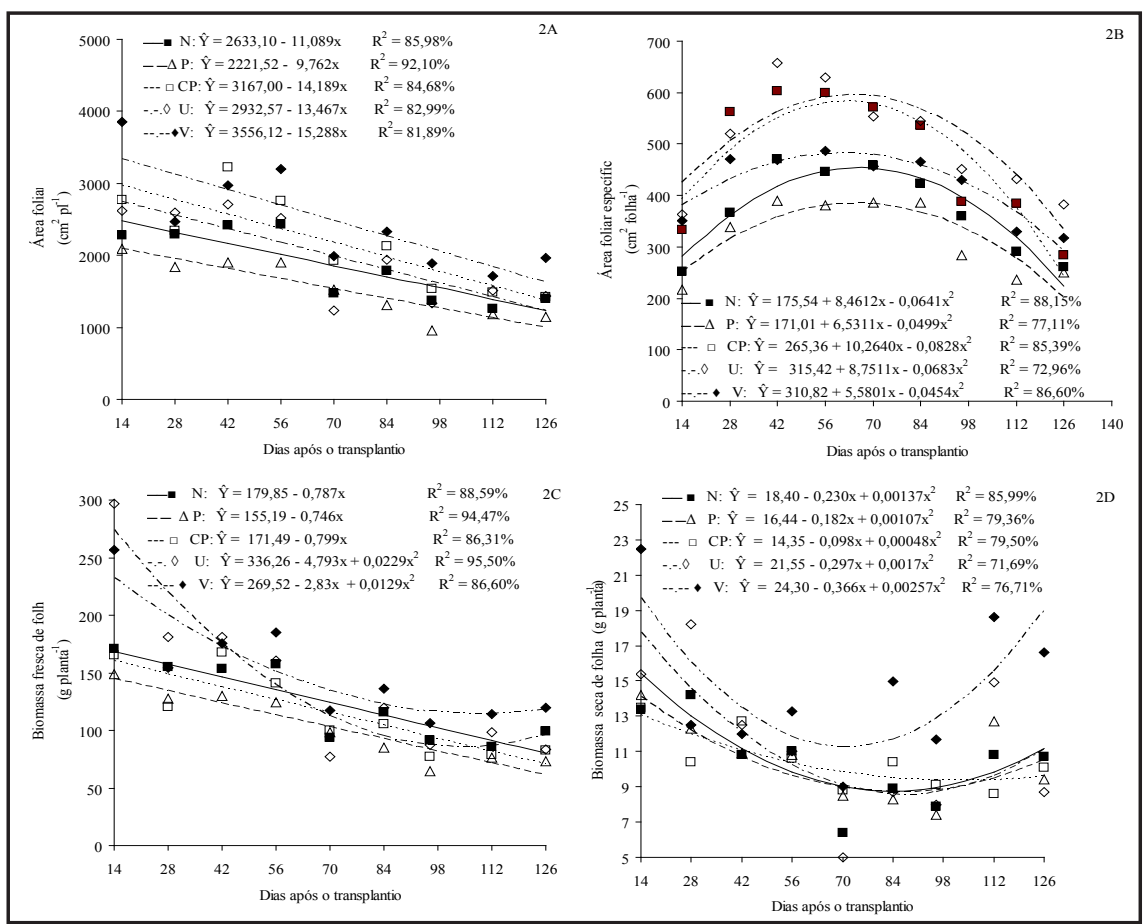

Figura 2. Diferenças entre as cultivares de couve Manteiga São José (N), Verde-Escura (P), IAC-Campinas (CP), Orelha de Elefante (U) e Vale das Garças (V) quanto à área foliar por planta e específica e biomassas fresca e seca de folhas dos 14 até 126 dias após a instalação do experimento [differences in the foliar area in a plant and specific foliar area and fresh- and dry-leaves weight from 14 to 126 days after the beginning of the assay among kale cultivars Manteiga São José (N), Verde-Escura (P), IAC-Campinas (CP), Orelha de Elefante (U) and Vale das Garças (V)]. Campinas, IAC, 2008. 
Tabela 1. Diferenças entre as cultivares de couve Manteiga São José (N), Verde-Escura (P), IAC-Campinas (CP), Orelha de Elefante (U) e Vale das Garças (V) quanto ao número de brotações dos 14 até 126 dias após a instalação do experimento e quanto ao número total de brotações (Brotações $\left(\mathrm{N}^{\circ}\right)$ ), de folhas colhidas (NF colhidas) e de total de folhas (NT folhas) e biomassas frescas (BFF) e secas das folhas (BFS) durante todo o experimento [differences in the number of sprouting from 14 to 126 days after the beginning of the assay and in total number of sprouting, in number of picked leaves and total number of leaves in the plant and fresh- and dry-leaves weight during the experiment among kale cultivars Manteiga São José (N), Verde-Escura (P), IAC-Campinas (CP), Orelha de Elefante (U) and Vale das Garças (V)]. Campinas, IAC, 2008.

\begin{tabular}{|c|c|c|c|c|c|c|c|c|c|}
\hline \multirow{2}{*}{ Cultivar } & \multicolumn{9}{|c|}{ Dias após a instalação do experimento (nº brotações/planta) } \\
\hline & 14 & 28 & 42 & 56 & 70 & 84 & 98 & 112 & 126 \\
\hline $\mathrm{N}$ & $1,1 b c^{2}$ & $8,0 \mathrm{a}$ & $3,8 b$ & $4,3 \mathrm{bc}$ & $3,5 \mathrm{bc}$ & $5,3 \mathrm{~b}$ & $4,1 \mathrm{a}$ & $8,6 a$ & $6,4 \mathrm{a}$ \\
\hline $\mathrm{P}$ & $4,9 \mathrm{a}$ & $2,9 \mathrm{~b}$ & $4,4 \mathrm{~b}$ & $6,4 \mathrm{ab}$ & $4,3 \mathrm{abc}$ & $5,3 \mathrm{~b}$ & $2,5 \mathrm{a}$ & $7,8 \mathrm{ab}$ & $5,9 \mathrm{a}$ \\
\hline $\mathrm{CP}$ & $0,7 \mathrm{c}$ & $5,4 \mathrm{a}$ & $4,3 b$ & $7,9 \mathrm{a}$ & $5,6 \mathrm{ab}$ & $2,5 \mathrm{c}$ & $3,8 \mathrm{a}$ & $4,1 b c$ & $4,6 \mathrm{a}$ \\
\hline $\mathrm{U}$ & $3,2 \mathrm{~b}$ & $7,4 a$ & $3,8 b$ & $2,8 \mathrm{c}$ & $2,9 \mathrm{c}$ & $5,3 b$ & $3,2 \mathrm{a}$ & $3,8 \mathrm{c}$ & $4,2 \mathrm{a}$ \\
\hline $\mathrm{V}$ & $1,8 \mathrm{bc}$ & $6,6 \mathrm{a}$ & $8,7 \mathrm{a}$ & $6,9 \mathrm{ab}$ & $6,9 \mathrm{a}$ & $10,0 \mathrm{a}$ & $3,5 \mathrm{a}$ & $4,6 a b c$ & $4,1 \mathrm{a}$ \\
\hline CV (\%) & 33,88 & 18,42 & 21,43 & 18,41 & 20,38 & 18,36 & 22,36 & 20,14 & 22,37 \\
\hline \multirow{2}{*}{ Cultivar } & \multicolumn{2}{|c|}{ Brotações $\left(n^{\underline{0}}\right)$} & \multicolumn{2}{|c|}{ NF colhidas } & \multicolumn{2}{|c|}{ NT folhas } & BFF & & BSF \\
\hline & \multicolumn{6}{|c|}{$\left(n^{0} \text { planta }^{-1}\right)^{1}$} & \multicolumn{3}{|c|}{$\left(\right.$ g planta $\left.^{-1}\right)$} \\
\hline $\mathrm{N}$ & \multicolumn{2}{|c|}{$45,2 b^{2}$} & \multicolumn{2}{|c|}{$47,34 \mathrm{~b}$} & \multicolumn{2}{|l|}{$100,81 \mathrm{a}$} & \multicolumn{2}{|l|}{$1123,0 b$} & $94,5 b$ \\
\hline $\mathrm{P}$ & \multicolumn{2}{|c|}{$44,4 b$} & \multicolumn{2}{|c|}{$45,31 \mathrm{c}$} & \multicolumn{2}{|l|}{$94,84 b$} & \multicolumn{2}{|l|}{$929,9 d$} & $94,5 b$ \\
\hline $\mathrm{CP}$ & \multicolumn{2}{|c|}{$38,9 \mathrm{c}$} & \multicolumn{2}{|c|}{$43,01 \mathrm{~d}$} & \multicolumn{2}{|l|}{$88,62 \mathrm{c}$} & \multicolumn{2}{|l|}{$1039,6 \mathrm{c}$} & $94,1 \mathrm{~b}$ \\
\hline $\mathrm{U}$ & \multicolumn{2}{|c|}{$36,7 \mathrm{c}$} & \multicolumn{2}{|c|}{$36,39 \mathrm{e}$} & \multicolumn{2}{|l|}{$64,31 \mathrm{~d}$} & \multicolumn{2}{|l|}{$1287,0 \mathrm{a}$} & $102,4 a$ \\
\hline $\mathrm{V}$ & \multicolumn{2}{|c|}{$53,0 \mathrm{a}$} & \multicolumn{2}{|c|}{$49,89 \mathrm{a}$} & \multicolumn{2}{|c|}{$102,38 \mathrm{a}$} & \multicolumn{2}{|l|}{$1365,7 \mathrm{a}$} & $131,6 \mathrm{a}$ \\
\hline $\mathrm{CV}(\%)$ & \multicolumn{2}{|c|}{8,90} & \multicolumn{2}{|c|}{2,63} & 3,81 & & 7,50 & & 10,9 \\
\hline
\end{tabular}

${ }^{1}$ Dados transformados em $\sqrt{x+1}$ para análise estatística, mas na tabela são apresentados os dados originais. ${ }^{2}$ Médias seguidas pela mesma letra na coluna, que comparam as cultivares dentro de cada época de avaliação, não diferem entre si pelo teste de Duncan a $5 \%$. [ ${ }^{1}$ data transformed in $\sqrt{x+1}$ to statistical analysis but in the table are presented the original data. ${ }^{2}$ means within columns followed by the same letters that compare the cultivars within each evaluation time, are not significant by Duncan test at 5\%].

plantas com menor diâmetro médio em todas as avaliações. Houve aumento no diâmetro médio das cultivares Verde Escura (P), IAC-Campinas (CP), Orelha de Elefante (U) e Vale das Garças (V) até, aproximadamente, 80 dias com redução após esse período. $\mathrm{O}$ diâmetro do caule das plantas da cultivar Manteiga São José $(\mathrm{N})$ diminuiu de acordo com um modelo logístico (Figura 1B). A avaliação do diâmetro do caule pode auxiliar no estudo para determinar o melhor período de tutoramento evitando assim perda de plantas pelo vento. Chakwizira (2007) verificou que o desenvolvimento de hastes de couve está relacionado com as condições do ambiente. Entretanto, segundo Trani (2008), as diferenças fisiológicas da couve podem estar relacionadas não apenas com as condições climáticas da região do cultivo, mas também às características botânicas da planta e suas respostas a tratos culturais como a adubação nitrogenada.

Em relação ao número de folhas colhidas, de modo geral, a cultivar Vale das Garças (V) foi mais produtiva (Figura
1C). Entretanto, cabe ressaltar que aos 84, 98 e 126 dias após o transplantio, a cultivar IAC-Campinas (CP) produziu o mesmo número de folhas que 'Vale das Garças' (V). A 'Orelha de Elefante' (U), em todas as épocas de avaliação, apresentou menor número de folhas comerciais. Em todas as cultivares foi observada redução no número de folhas colhidas em função do tempo, sendo estimado que os menores valores foram obtidos entre 83 e 86 dias após o transplantio (Figura 1C). Os menores valores obtidos no número de folhas colhidas coincidem com o aumento da temperatura que se deu no final de outubro e início de novembro. Nesse período as temperaturas máximas e mínimas variaram, dentro da casa de vegetação, de 27,6 a $34,2^{\circ} \mathrm{C}$ e 16,2 a $21,8^{\circ} \mathrm{C}$ respectivamente, para os meses de outubro e início de novembro.

De modo geral, a cultivar Vale das Garças (V) foi a mais produtiva e a 'Orelha de Elefante' (U) a que apresentou o menor número total de folhas em todas as avaliações (Figura 1D).
Para todas as cultivares avaliadas foi observada redução no número total de folhas de acordo com uma equação do segundo grau, obtida de equação quadrática, estimando-se que valores mínimos seriam observados aos 85,89 , 92,88 e 92 dias, respectivamente para as cultivares Manteiga São José (N), Verde Escura (P), IAC-Campinas (CP), Orelha de Elefante (U) e Vale das Garças (V) (Figura 1D).

Nas avaliações de área foliar por planta, em geral, verificou-se que a cultivar Vale das Garças (V) foi a que apresentou maiores valores (Figura 2A). Entretanto, aos 28, 42, 70, 84, 98 e 112 dias a 'IAC-Campinas' (CP) não diferiu da 'Vale das Garças' (V). A cultivar Verde-Escura (P) foi a que apresentou menor área foliar por planta em todas as épocas de avaliação, mas aos 70 dias, a Manteiga São José (N) e a Orelha de Elefante (U) também apresentaram valores de área foliar similares à da 'VerdeEscura' (P). Aos 126 dias, no final do ciclo da couve, as cultivares Manteiga São José (N), Verde-Escura (P), IAC- 
Campinas (CP) e Orelha de Elefante (U) apresentaram área foliares inferiores à da Vale das Garças (V). Para todas as cultivares houve redução linear na área foliar por planta em função do tempo (Figura 2A). As oscilações térmicas podem ter afetado o desenvolvimento das couves. No entanto, embora tenha havido reduções na área foliar, a couve 'Vale das Garças' (V) mostrou-se mais adaptada que os demais materiais às variações térmicas ocorridas no período.

Verificou-se que, na maioria das avaliações, a 'Orelha de Elefante' (U) apresentou maior área foliar específica não diferindo até os 112 dias da 'IACCampinas' (CP) (Figura 2B) sendo superiores às da 'Manteiga São José' (N) e da 'Verde-Escura' (P). Embora a cultivar 'Orelha de Elefante' (U) tenha apresentado maior área foliar específica, seu número de folhas foi menor que dos outros materiais. Dos 14 aos 42 dias, a área foliar específica das cultivares IAC-Campinas (CP), Orelha de Elefante (U) e Vale das Garças (V) não diferiram estatisticamente entre si. Para todas as cultivares houve aumento da área foliar específica de acordo com uma equação do segundo grau, obtida de equação quadrática, estimando-se que valores máximos seriam observados aos 66,65 , 61, 64 e 61 dias, respectivamente para as cultivares Manteiga São José (N), Verde Escura (P), IAC-Campinas (CP), Orelha de Elefante (U) e Vale das Garças (V) (Figura 2B).

Até os 28 dias após o transplantio, a cultivar Orelha de Elefante (U) apresentou biomassa fresca de folha superior à dos outros genótipos (Figura 2C). Na maioria das avaliações, a cultivar Vale das Garças (V) apresentou biomassa fresca de folhas superior e a cultivar Verde-Escura $(\mathrm{P})$ inferior à dos outros genótipos (Figura 2C). Cabe ressaltar que, aos 42 e 84 dias após o transplantio, as biomassas frescas das cultivares IAC-Campinas (CP), Orelha de Elefante (U) e Vale das Garças (V) não diferiram estatisticamente entre si. As biomassas frescas das cultivares Manteiga São José (N), Verde-Escura (P) e IAC-Campinas (CP) foram linearmente reduzidas com o tempo. Para 'Orelha de Elefante' (U) e 'Vale das Garças' (V) estimou-se que houve redução nas biomassas frescas de folhas até, respectivamente, aos 104 e 110 dias após o transplantio com posterior aumento (Figura 2C).

Em relação à biomassa seca de folhas, exceto aos 28, 4270 e 112 dias após o transplantio, a 'Vale das Garças' (V) apresentou valores mais elevados que as demais (Figura 2D). Aos 28 dias, a biomassa seca da cultivar Orelha de Elefante $(\mathrm{U})$ foi superior à das demais e aos 42 dias não houve diferença entre as cultivares para essa variável. Aos 70 dias, a biomassa seca da cultivar Vale das Garças (V) não diferiu das obtidas pelas 'Verde-Escura' (P) e 'IAC-Campinas' (CP). Houve redução na biomassa seca de folhas até 84, 85, 102, 87 e 71 dias após o transplantio, respectivamente para as cultivares Manteiga São José (N), Verde-Escura (P), IAC-Campinas (CP), Orelha de Elefante (U) e Vale das Garças (V) com posterior aumento.

As plantas de couve apresentaram brotações nas axilas das folhas e a partir das raízes. Não houve diferença entre cultivares quanto ao local de emissão de brotações (dados não apresentados). Em algumas avaliações, as emissões de brotações eram apenas observadas a partir das raízes e em outras em ambos os locais. Entretanto, as mudas produzidas nas axilas das folhas foram sempre maiores que as provenientes das raízes. Não houve constância nas respostas das cultivares quanto ao número de brotações emitidas, e nem interação entre época de avaliação e cultivares (Tabela 1).

Em relação ao número total de brotações, de folhas colhidas e total de folhas formadas foi observado que a cultivar Vale das Garças (V) foi a mais produtiva e a 'IAC-Campinas' (CP) e a 'Orelha de Elefante' (U) as menos (Tabela 1). A cultivar Manteiga São José (N) apresentou número total de folhas que não diferenciou estatisticamente da 'Vale das Garças' (V). As cultivares Orelha de Elefante (U) e Vale das Garças (V) foram superiores com maiores biomassas fresca e seca de folhas e a 'Verde-Escura' (P) e 'IAC-Campinas' (CP), as menores biomassas frescas (Tabela 1). Concluiu-se que as cultivares Orelha de Elefante (U) e Vale das Garças
(V) constituem boas alternativas para a produção de couve.

\section{REFERÊNCIAS}

CAMARGO ANMMP; CAMARGO FP; CAMARGO FILHO WP. 2008. Distribuição geográfica da produção de hortaliças no Estado de São Paulo: participação no País, concentração regional e evolução no período 1996-2006. Informações Econômicas 38: 28-35.

CAMARGO LS. As hortaliças e seu cultivo. 1984. $2^{a}$ ed rev. aumentada. Campinas: Fundação Cargill. p.210.

CAMARGO FILHO WP; CAMARGO, FP. 2009. Análise das alterações na cadeia de produção de hortaliças em São Paulo,1995-2007. IEA/ CATI. Anuários, banco de dados. Disponível em: www.iea.sp.gov.br. Acessado em 27 de abril de 2009.

CHAKWIZIRA, E. 2008. Growth and development of 'Pasja' and kale crops with two methods and four rates of phosphorus $(P)$ application. Lincoln: LINCOLN UNIVERSITY. (Tese mestrado). Disponível em: http:// researcharchive.lincoln.ac.nz/dspace/handle/ 10182/929. Acessado: 16 de abril de 2009.

FILGUEIRA FAR. 2000. Novo manual de olericultura. Viçosa: UFV. 420p.

HUSSAR GJ; PARADELA AL; SERRA W; JONAS TC; GOMES JPR. 2004. Efeito do uso do efluente de reator anaeróbio compartimentado na fertirrigação da couve. Revista Ecossistema 29: 65-72.

LEFSRUD M; KOPSELL D; WENZEL A; SHEEHAN J. 2007. Chances in kale (Brassica oleracea L. var. acephala) carotenoid and chlorophyll pigment concentrations during leaf ontogeny. Scientia Horticulturae 112: 136-141.

LORENZ OA; MAYNARD DN. 1988. Handbook for vegetable growers. $3^{\mathrm{a}} \mathrm{ed}$. New York: John Wiley-Interscience Publication. 456p.

NIEUWHOF M. 1969. Cole Crops. Londres: World Crops Books. p.92-95.

STEEL RGD; TORREI JH. 1980. Analysis of variance. IV: Split-plot designs and analysis. In: STEEL RGD; TORREI JH (eds). Principles and procedures of statistics. $2^{a}$ ed. New York: Mc Graw Hill. p.377-400. (Capítulo 16).

TAVARES M; TRANI PE; SIQUEIRA WJ. 1998. Couve. Brassica oleracae L. var. acephala. In: FAHL JI; CAMARGO MBP; PIZZINATTO MA; BETTI JA; MELO AMT; DEMARIA IC; FURLANI AMC (eds). Instruções agrícolas para as principais culturas econômicas. $6^{\mathrm{a}} \mathrm{ed}$. rev. atual. Campinas: Instituto Agronômico. (Boletim 200). p.201-202.

TRANI PE. 2008. Avaliação agronômica, organoléptica e caracterização botânica da coleção de germoplasma de couve de folhas do IAC. São Paulo: Secretaria de Agricultura e Abastecimento. 3p. (Projeto SIGA, NRP 137). 